\title{
Optimisation of Operational Parameters of a Spiral Classifier Using Design of Experiment (DOE)*
}

\author{
${ }^{1} \mathrm{~K}$. Ackah, ${ }^{1} \mathrm{C}$. Owusu and ${ }^{1} \mathrm{~F}$. Amoah \\ ${ }^{1}$ University of Mine and Technology, P. O. Box 237, Tarkwa
}

Ackah, K., Owusu, C. and Amoah, F. (2020), "Optimisation of Operational Parameters of a Spiral Classifier Using Design of Experiment (DOE)”, Ghana Mining Journal, Vol. 20, No. 1, pp. 45 - 50.

\begin{abstract}
Classifying Mn Ore to improve upon the grade and the properties has become a crucial activity for the Mn industry since it increases the market value of the ore. Ghana Manganese Company (GMC) has renovated their oxide washing plant by integrating it with a spiral classifier to make a batch system operating process. Particle size of $<3.35 \mathrm{~mm}$ (Mn grade of 43$47 \%$ ) obtained from the primary section of the plant served as feed to the classifier and with the plant condition (i.e. at 60 min washing time, $30 \mathrm{rev} / \mathrm{min}$ speed of spirals and feed tonnage of $6 \mathrm{t}$ ), Mn grade of $49 \%$ was achieved. This paper focused on the optimisation of some selected operational parameters of the classifier to obtain a Mn grade $>50 \%$ using Design of Experiment (DOE). Series of test works were designed using the DOE for the classifier using the constraints of washing time (30-90 $\mathrm{min})$, speed of spirals (20-40 rev/min) and feed tonnage (6-9 t). The outcome of the test work after simulation showed that all the selected parameters had a great influence on $\mathrm{Mn}$ grade. The spiral speed and feed tonnage correlated negatively to the Mn grade with washing time correlating positively. Operating the spiral classifier at a feed rate, spiral speed and washing time of $6 \mathrm{t}, 25 \mathrm{rev} / \mathrm{min}$, and $30 \mathrm{~min}$, respectively, yielded Mn grade of 53\%. A Confirmatory test using the established conditions gave a Mn grade of $53 \%$, which is a $4 \%$ increment in the previous Mn grade which was $47 \%$. The outcome of the studies is the new established operational conditions which is adhered to by the plant, producing a manganese concentrate grade ranging between $52-54 \%$.
\end{abstract}

Keywords: Design of Experiment (DOE), Spiral Classifier, Grade, Manganese

\section{Introduction}

Manganese is the 10th most abundant mineral in the world of which some are ubiquitous in the soil and exerts considerable influence on the composition and chemical behaviors of the ore itself (Skinner et al., 1992). The mining of manganese ore on a large scale always comes with unwanted minerals like clay, iron, silica and phosphorus thereby requiring upgrading to separate these unwanted minerals. Beneficiation methods like concentration, classification and others can be employed to enhance the removal of these gangue minerals from the manganese ore in mineral processing.

Classification is described as the separation of mixtures of minerals into two or more products based on the velocity with which they fall through a fluid medium (Heiskanen, 1979). Following liberation of the mineral of interest from the gangue minerals by comminution and screening, removal of the gangue minerals by their physical properties like size and specific gravity is attempted by a classification process (Gupta, 2006). Wet classification methods are used during ore dressing and hydrometallurgical processes. It is employed when separating sand from slimes, concentrating of smaller heavy-gravity mineral particles from large light-gravity mineral particles and sort solids of long range screen sizes into short range fraction ( Jones, 1985; Swain, 2011).
Size classification equipment are designed to split a feed of product material into coarse and fine products. They are subject to capacity limitations and must be considered when the performance of new or existing classification equipment is being evaluated (King, 2012). Many dissimilar classifiers have been built for industrial purposes. Based on their direction and flow of carrying current, they are grouped into non-mechanical classifiers, cyclones and mechanical classifiers (Wills, 2006). Spiral classifier (Fig. 1), a mechanical classifier, is one common equipment used for classification in most processing industries. This equipment has one or more spirals revolving slowly and freely on an inclined tank without touching the sides or the bottom. Its classification is based on the size and the specific gravity of the particles in the pool. It has a maintain mechanism for continuously conveying and draining of the settled material by the revolving spirals and simultaneously decants water and fine materials over the overflow weir. This equipment is generally preferred because it produces less turbulence in the settling tank, which is good for finer separations. In addition, the materials do not slide back as it occurs in the rake classifier 


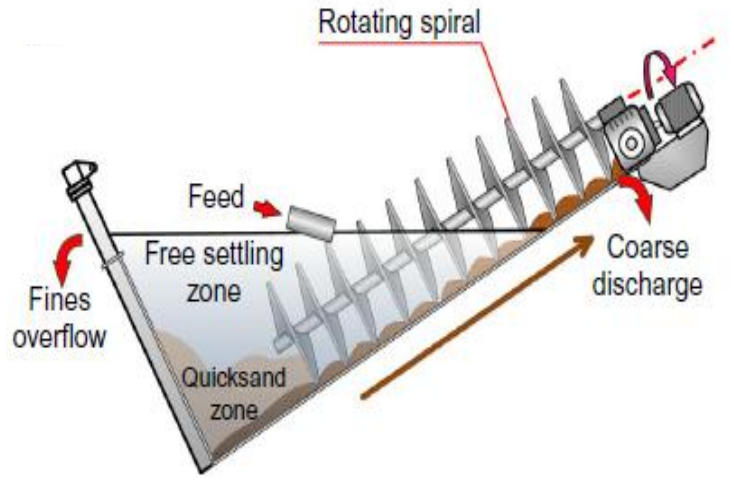

Fig. 1 A typical Spiral Classifier (Wills, 2006)

Records indicate that since 1916 when exploitation began, over 27 million tonnes of high grade $(52 \%$ $\mathrm{Mn})$, low grade $(48-50 \% \mathrm{Mn})$ and other grades (46\% $\mathrm{Mn}$ and $42-45 \% \mathrm{Mn}$ ) manganese oxides were produced from Ghana Manganese Company, GMC (Nsuta mine) for the mineral market (Kesse, 1985). This was after beneficiation methods like concentration, classification and others have been utilized to enhance and enrich the manganese ore from its associated gangue minerals during processing. This spiral classifier was recently integrated into the processing plant at Ghana Manganese Company, Nsuta mine (GMC) to make a batch processing plant to serve the purpose of upgrading their manganese ore for the mineral market. Intermediate product with particle size of $<3.35 \mathrm{~mm}$ and manganese grade of $43.9 \%-47.8 \%$ obtained from the primary section served as feed material to the spiral classifier. Processes at the spiral classifier was adjusted to give final product grades ranging between $50-52 \% \mathrm{Mn}$ after commissioning but recently the grade has reduced to $48-49 \% \mathrm{Mn}$.

This paper therefore seeks to optimize the operational parameters (speed of the spirals, feed tonnage and the resident time for washing) of the spiral classifier incorporated in the oxide washing plant to upgrade the final product grade (grade $>51$ ) by employing the Design of Experiment, DOE.

\section{Resources and Methods Used}

\subsection{Materials and Equipment}

Intermediate product with particle sizes ranging from 0.075-3.35 $\mathrm{mm}$ and manganese grade of $43.9 \%-49.8 \%$ obtained from the primary crusher section served as feed material to the Spiral Classifier. The Spiral Classifier used for the study was manufactured by Nick and Paul.

\subsection{Designing of Test Works}

Prior to test work design, visit to the oxide plant at Ghana Manganese Company (GMC) were made with the aim of getting acclimatize with the current operations at the plant. The Spiral classifier was operated in batch mode. The control parameters of the spiral classifier were critically observed and studied to understand spiral classifier operation. The adjustable parameters at the classifier section were the feed particle size, amount of water supplied to the classifier, angle of inclination of the classifier, feed tonnage, the speed of the spirals and the washing time.

This study focused on feed tonnage into the classifier, the speed of the classifier spirals and washing time since the plant was already in operation. The design of experiment (DOE), which uses statistical technique in designing experiments to get a controlled set of tests designed to model and explore the relationship between factors that affects a process, was used to design an organized and controlled series of test work (Table 1). During the design of test work, the spiral speed, feed tonnage and washing time were varied using DOE between 20-40 rev/min, 6-8 $\mathrm{t}$ and washing time respectively. After washing period for every test run, a speed of $40 \mathrm{rev} / \mathrm{min}$ was used to discharge the classified product from the classifier.

Table 1 The Test Works for the Classifier

\begin{tabular}{|c|c|c|c|c|}
\hline Test & $\begin{array}{c}\text { Spiral } \\
\text { speed, } \\
(\mathbf{r e v / m i n})\end{array}$ & $\begin{array}{c}\text { Feed } \\
\text { rate, } \\
\text { (T) }\end{array}$ & $\begin{array}{c}\text { Washing } \\
\text { time, } \\
(\mathbf{m i n})\end{array}$ & $\begin{array}{c}\text { Manganese } \\
\text { grade } \\
(\boldsymbol{\%})\end{array}$ \\
\hline 1 & 40 & 6 & 90 & - \\
\hline 2 & 20 & 8 & 90 & - \\
\hline 3 & 30 & 7 & 90 & - \\
\hline 4 & 30 & 7 & 60 & - \\
\hline 5 & 40 & 6 & 30 & - \\
\hline 6 & 20 & 7 & 60 & - \\
\hline 7 & 30 & 6 & 60 & - \\
\hline 8 & 30 & 8 & 60 & - \\
\hline 9 & 40 & 7 & 60 & - \\
\hline 10 & 30 & 7 & 60 & - \\
\hline 11 & 40 & 8 & 30 & - \\
\hline 12 & 30 & 7 & 30 & - \\
\hline 13 & 20 & 6 & 90 & - \\
\hline 14 & 20 & 6 & 30 & - \\
\hline 15 & 40 & 8 & 90 & - \\
\hline 16 & 20 & 8 & 30 & - \\
\hline
\end{tabular}




\section{Results and Discussion}

\subsection{Manganese (Mn) Grade}

Intermediate product with particle size of $<3.35$ $\mathrm{mm}$ and manganese grade of $43.9 \%$ - $47.8 \%$ served as feed material to the spiral classifier. Samples that were taken for chemical analysis and particle size analysis during the commissioning gave results within the ranges stated above. Fig. 2 shows the Mn grade for the different test conditions designed with DOE. The ore sample was subjected to classification using the spiral classifier at varying washing speed (20-40 rev/min), washing residence time (30-90 mins) and the feed tonnage also (6-8 t) to determine the optimum operational conditions for maximum $\mathrm{Mn}$ grade. The result of the various test gave Mn grade (\%) ranging between $49 \%$ and $53 \%$ (Fig. 2).

\subsection{Influence of Operational Parameters on Spiral Performance}

The results (Fig. 2) obtained were modelled using the Design of experiment (DOE) to ascertain the influence of each parameter (feed rate, spiral speed and washing time) on the spiral classifier performance. Fig. 3 shows the prediction profile for manganese grade as function of spiral speed, feed rate and washing time. The solid black lines show the changes to expect in manganese grade when a parameter is varied and all other parameters held constant. The blue lines represent the $95 \%$ confidence band. The steepness of the black line for any of the parameters signifies its importance or effect on manganese grade.

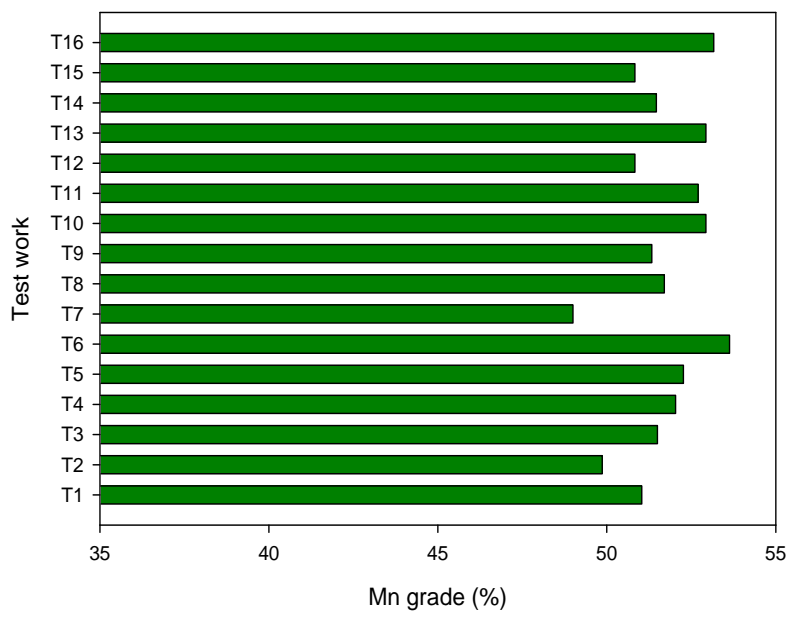

Fig. 2 Mn grade (\%) for various Spiral Classification Test

From Fig. 3, it is clear that all the parameters selected had an influence on the performance of the classifier. Speed of the spirals has negative correlation with $\mathrm{Mn}$ grade. An increase in the spirals speed significantly decreases the manganese grade. The function of the spiral during classification is to agitate the pulp and transport the settled grains away from the separating zone. Therefore, with increased spiral speed during washing, the materials do not get enough time at the classification section to undergo classification. This causes the spirals to carry all the gangue and concentrate to the discharge end of the classifier and report as product. The later contributing to a reduction in the overall manganese grade. The data in Fig. 3 also show that the amount of material fed into the classifier correlate negatively to $\mathrm{Mn}$ grade. This is expected since increasing the amount of material in the classifier causes crowding and increased pulp density at the classification section of the classifier.

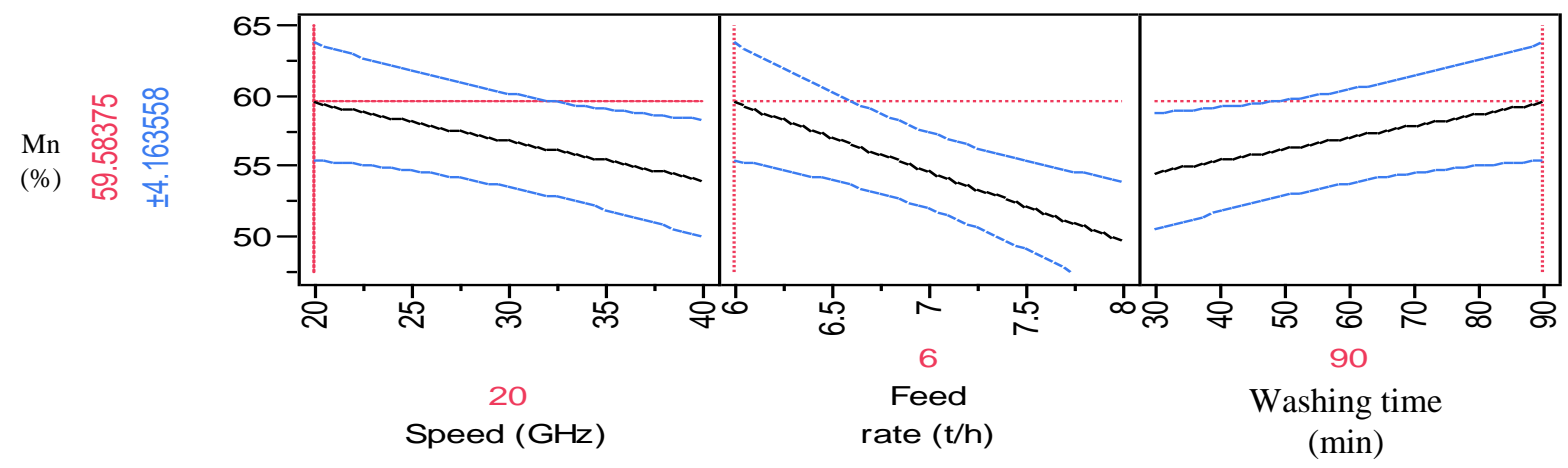

Fig. 3 Prediction profile for Mn grade (\%) as A Function of Speed, Feed Rate and Washing Time 
Generally, an increase in the proportion of solids in a pulp causes hindered settling and consolidation trickling, which subsequently decreases the settling rate of the particles. Besides, at high feeding rate, the system begins to behave as a heavy liquid whose density is that of the pulp rather than that of the carrier liquid. Because of the high density and viscosity of the slurry through which a particle must fall, selectivity between the gangue and value materials reduces (Marsden and House, 2006). The resident washing time for the batch process had a positive correlation with the $\mathrm{Mn}$ recovery. This is obvious because when the material is allowed to stay in the classifier for a longer period, there will be enough time for efficient separation between valued and gangue materials to take place.

\subsection{Optimisation of Spiral Performance}

The prediction profile in Fig. 4 clearly showed that all the operational parameters considered in the study greatly influence the performance of the spiral classifier used at GMC. To determine the optimum conditions for high Mn grade, simulation of the data in Fig. 2 was done using the simulation package of the DOE at the current plant feed rate of
$6 \mathrm{t} / \mathrm{h}$. The outcome of the simulation is presented in Fig. 4. At $6 \mathrm{t} / \mathrm{h}$ feed rate and a reduced spiral speed and washing time of $20 \mathrm{rev} / \mathrm{min}$ and $30 \mathrm{~min}$ respectively, the spiral classifier was optimized to produce Mn grade of approximately $54 \% \pm 0.5$.

Based on the predicted optimal operational conditions obtained from DOE, a confirmatory test was performed at the classification plant of GMC. Results from the confirmation test run at feed rate of 6 tonnes showed significant improvement in the Mn grade at the selected spiral speed of $20 \mathrm{rev} / \mathrm{min}$ and washing time of 30 min (Fig. 5). By changing the baseline conditions of the spiral clasifier to current condition, gave a $4 \%$ increment in $\mathrm{Mn}$ grade. Thus, the Mn grade increased from $49 \%$ under the baseline condition (plant condition) to $53 \%$ as against the predicted value of $53.7 \%$. Again, the use of the current condition will significantly reduce the plants operational cost and increase throughput since less energy and washing time is required compared to the baseline conditions employed at the plant. Currently the plant has adhered to the new parameters that have been provided and they are getting a Mn grade of between $53-54 \%$.

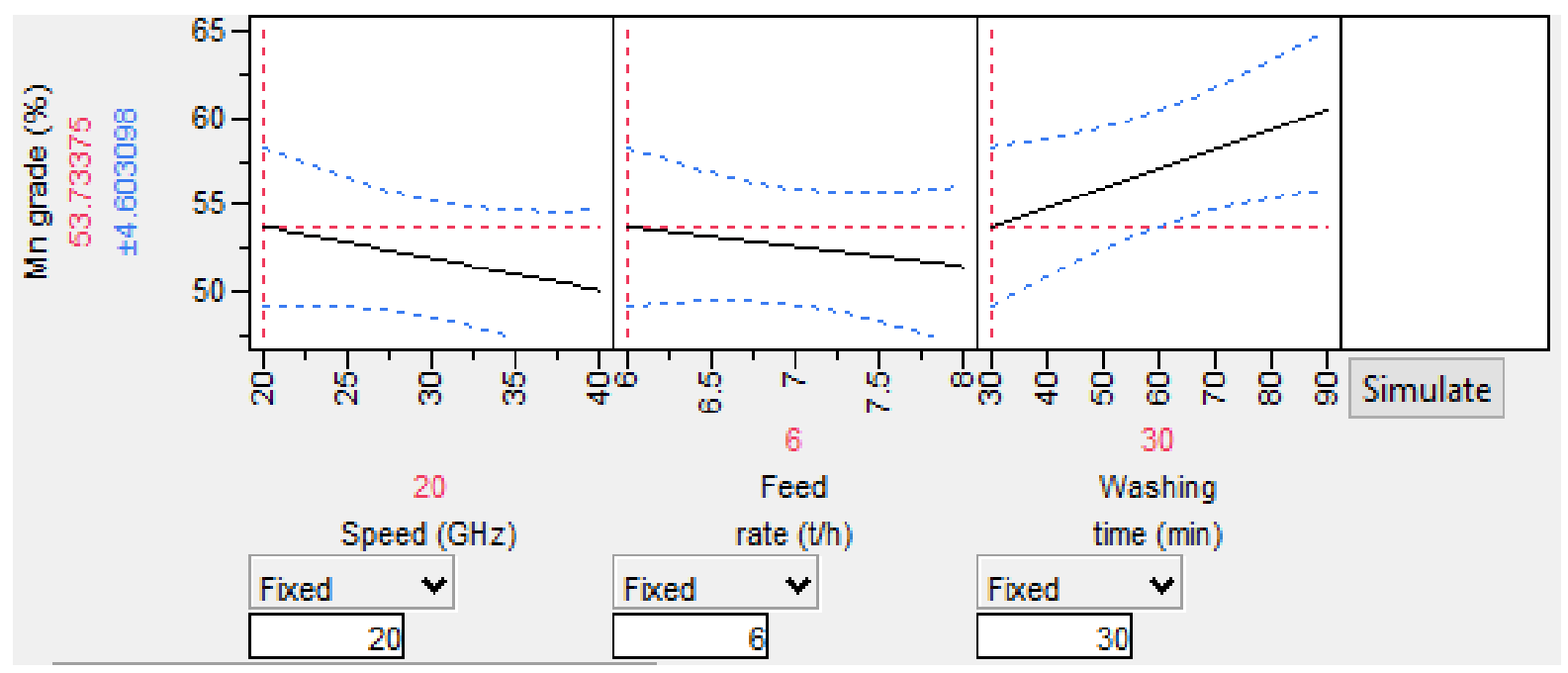

Fig. 4 Simulated Prediction Profile for Mn Grade (\%) as a Function of Spiral Classifier Operational Parameters 


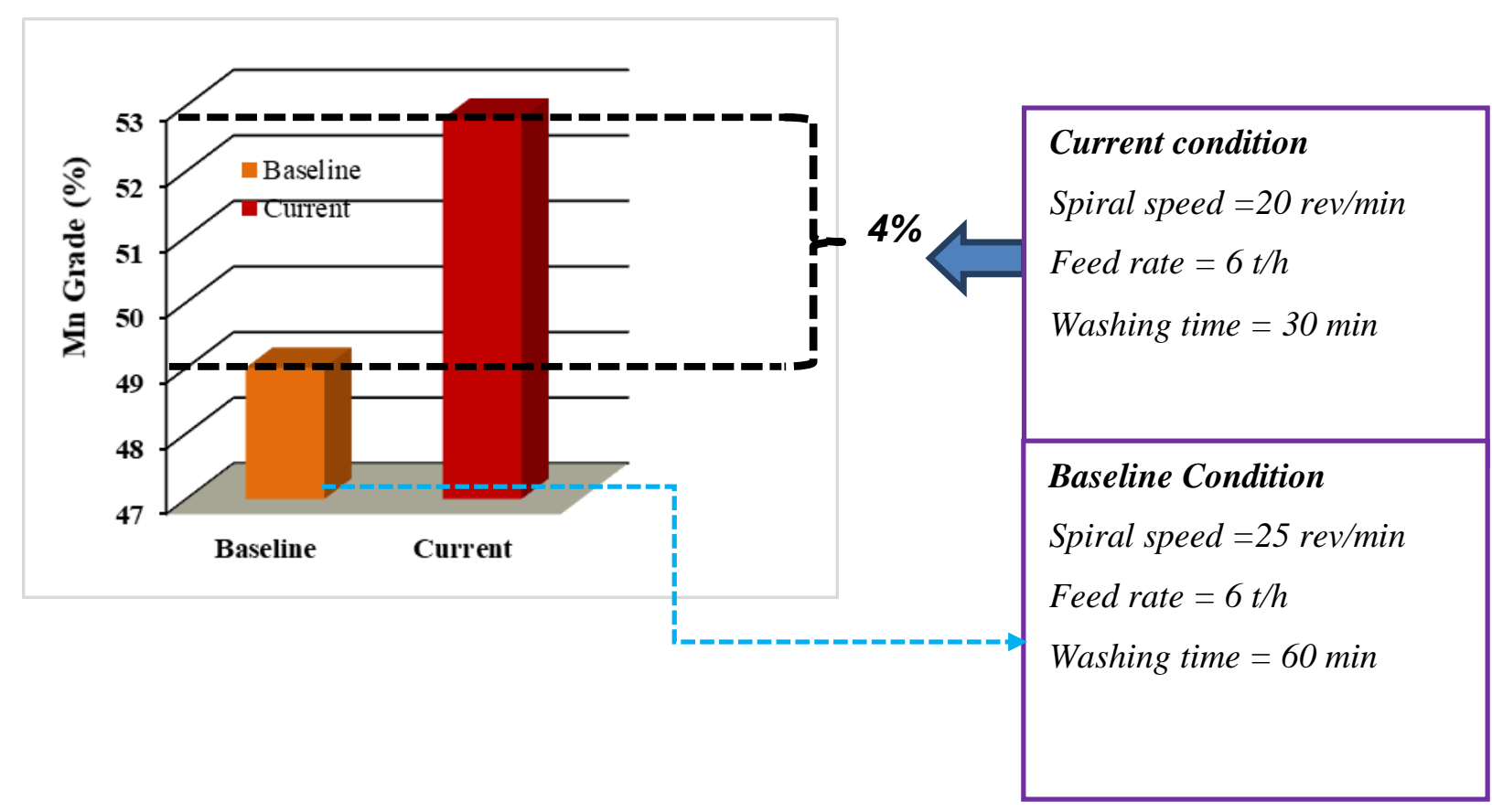

Fig. 5 Mn Grade (\%) as a Function of Plant Condition and Simulated Condition

\section{Conclusions and Recommendations}

The goal of the study was to access the influence of operational parameters such as spiral speed, feed tonnage rate and washing time on the performance of the Spiral classifier installed at Ghana Manganese Company (GMC) and improve on the manganese grade. Through the use of Design of Experiment (DOE) an organized and series of controlled test were run and results modelled.

The outcome showed that Mn grade (\%) is greatly influenced by the spiral speed, feeding rate and washing time. Whereas a positive correlation was observed between washing time and Mn grade, feed rate and spiral speed correlated negatively to the manganese grade.

Improvement in Mn grade (from $49 \%$ to $53 \%$ ) was achieved at spiral speed, feed rate and washing time of $20 \mathrm{rev} / \mathrm{min}, 6 \mathrm{t} / \mathrm{h}$ and $30 \mathrm{~min}$, respectively. A confirmation test run also confirmed the claim. Currently the plant has adhered to the new parameters that have been provided and they are getting a Mn grade of between $52-54 \%$.

\section{Acknowledgements}

The authors wish to express their sincere and innermost gratitude to the Ghana Manganese Company (GMC) for giving us entry to their plant, the Chief Metallurgist at Ghana Manganese Company Ltd, Mr. Seidu Abubakar for the enormous role he played in making this work a success. We would like to say thank you to entire staff at the oxide washing plant for their inflicting cooperation.

\section{References}

Gupta A. and Yan S. D. (2006), Mineral Processing Design and Operation: An Introduction, Elsevier Publishers, 718 pp.

Haldar S. K. (2012), Mineral Exploration: Principles and Applications, Newnes Publishers, $372 \mathrm{pp}$.

Heiskanen, K., 1979, "Two stage classification." World Mining, Vol. 32, pp 44-46.

Jones, D. A., Corrosive Wear in Wet Grinding Systems, Journal of Metals, Volume 37, No. 6, June, 1985, pp. 20-23.

Kesse, G. O. 1985. The Mineral and Rock Resources of Ghana. Balkema, Rotterdam, 610 pp.

King R. P. (2012), Modeling and Simulation of Mineral Processing Systems, Elsevier Publishers, 416 pp.

Marsden, J. and House, I. (2006), The Chemistry of Gold Extraction, second edition, Society for Mining, Metallurgical and Exploration, Inc. Littleton, Colorado, USA, $651 \mathrm{pp}$.

Skinner H. C. W., Fitzpatrick R. W., Post J. E. (1992) Biomineralization, Processes of Iron and Manganese, eds Skinner H. C. W., Fitzpatrick R. W., Catena Verlag, Cremlingen-Destedt, Germany, pp 51-73.

Swain (2011), Mechanical Operations, Tata McGraw-Hill Education Publishers, 324 pp.

Wills, B. A. and Napier-Munn, T. J. (2006), Wills' Mineral Processing Technology, 7th edition, 
Butterworth-Heinemann, Armstedam, London, 486 pp.

\section{Authors}

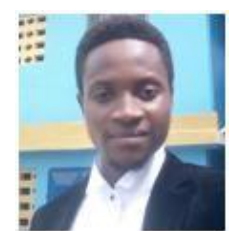

K. Ackah is currently a Research Assistant in the Minerals Engineering Department, University of Mines and Technology (UMaT), Tarkwa, Ghana. He holds a Bachelor of Science, Second Class Upper Degree in Minerals Engineering from the UMaT. He has interest in research works pertaining to mineral processing including, froth flotation, hydrometallurgy and high temperature processes in metallurgy.

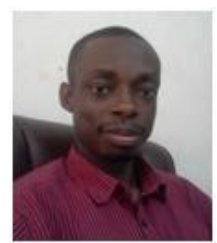

C. K. Owusu is currently a Senior Lecturer and a Researcher in the Minerals Engineering Department, University of Mines and Technology (UMaT), Tarkwa, Ghana. He holds a PhD in Minerals and Materials Engineering from the University of South Australia (UniSA) and a Bachelor of Science Honours Degree in Minerals Engineering from UMaT. He is a member of the West African Institute of Mining, Metallurgy and Petroleum (WAIMM). His current research interest includes oxygen optimisation in gold processing, fine particle flotation of sulphide minerals, surface chemistry of minerals, statistical analysis and modeling of metallurgical data.

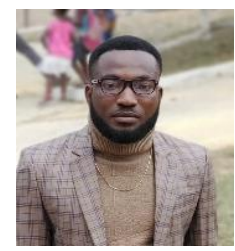

F Amoah is currently the plant metallurgist at Ghana Manganese Company (GMC). He holds a Bachelor of Science, Second Class Upper Degree in Minerals Engineering from the University of Mines and Technology (UMaT), Tarkwa, Ghana. He is a member of the Australasian Institute of Mining and Metallurgy (AUSIMM) and Ghana Institute of Engineers $(\mathrm{GHiE})$. He has interest in extractive metallurgy and process optimisation. 